\title{
MARKET DEFINITION AND THE ECONOMIC Effects of Special AcCess Price REGULATION
}

\author{
By T. Randolph Beard* \\ George S. Ford, $\mathrm{PhD}^{\dagger}$ \\ Lawrence J. Spiwak, Esq.
}

Abstract: Market definition is an essential ingredient to competitive and regulatory analysis. Yet, there is significant disparity regarding the definition of the relevant geographic market for high-capacity circuits, commonly referred to as Special Access services. Given the present debate over expanding price regulation in this sector, the importance of market definition on the expected economic effects of regulation is worth evaluating. In this article, we demonstrate that if geographic markets are "location specific" and supplied by a monopolist as the proponents of regulation claim, then price regulation reduces economic welfare in all instances. That is, even with monopoly supply, regulation offers no improvement in economic welfare, meaning the debates over the extent of competition and profit margins in such markets are irrelevant. The effect of regulation is mostly to transfer profits from sellers to buyers, so the debate appears to be largely a squabble over rents. That said, every $\$ 1$ of transfer costs more than $\$ 1$ to society, so regulation reduces welfare. This analysis demonstrates that the present case for regulating high-capacity services is woefully inadequate and poorly conceived.

\footnotetext{
* Senior Fellow, Phoenix Center for Advanced Legal \& Economic Public Policy Studies; Professor, Department of Economics, Auburn University, Auburn, Alabama.

Chief Economist, Phoenix Center for Advanced Legal \& Economic Public Policy Studies. $\$$ President, Phoenix Center for Advanced Legal \& Economic Public Policy Studies. The views expressed in this paper are the authors' alone and do not represent the views of the Phoenix Center or its Staff. We are indebted to Phoenix Center Senior Fellow Professor Michael Stern for his assistance in formulating the economic model presented in this paper.
} 


\section{TABLE OF CONTENTS}

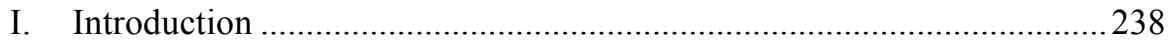

II. The Welfare Effects of Price Regulating High Capacity Circuit ............ 245

A. Two Key Assumptions: Point-to-Point Geographic Markets and Monopoly Source of Supply .......................................................246

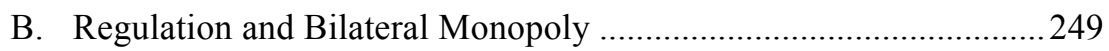

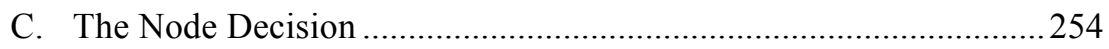

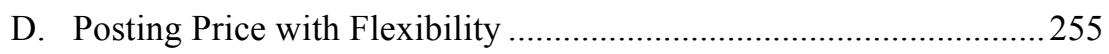

E. Dividing the Gains from Trade.......................................................256

F. Comparison to the Textbook Monopoly Case .................................256

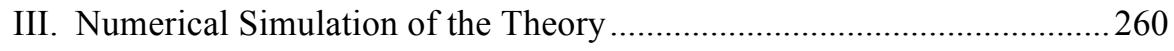

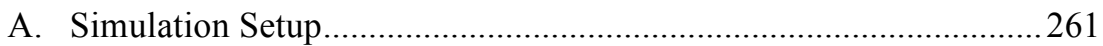
B. Results with Seller's Right to Refuse .............................................262
C. Results with Seller Mandate to Provide ..........................................262

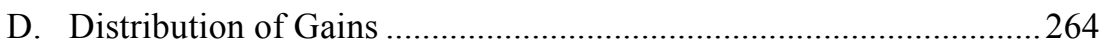

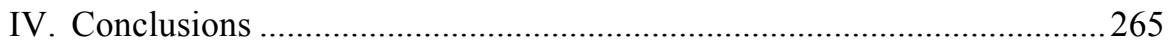

\section{Introduction}

Businesses and other telecom service providers, such as wireless carriers, use high capacity "special access" circuits to provide reliable and guaranteed bandwidth between business locations, cell phone towers and, increasingly, the public Internet. ${ }^{1}$ The Federal Communications Commission ("FCC") traditionally regulated high capacity circuits pursuant to rate-of-return and, later, price cap regulation, but beginning in 1999 the FCC began to grant incumbent telephone exchange carriers ("incumbent LECs") pricing flexibility on a metropolitan statistical areas ("MSAs") basis if the incumbent LEC documented the presence of alternative competitive facilities. ${ }^{2}$

1 See In re Special Access for Price Cap Local Exchange Carriers, Report and Order, 27 F.C.C.R. 10,557, 10,558 n.1 (Aug. 22, 2012) [hereinafter Special Access Order] ("The term 'special access services' encompasses all services that do not use local switches; these include services that employ dedicated facilities that run directly between the end user and an IXC's point of presence, where an IXC connects its network with the LEC network, or between two discrete end user locations.").

2 In re Access Change Reform; Price Cap Performance Review for Local Exchange Carriers; Interexchange Carrier Purchases of Switched Access Services Offered by Competitive Local Exchange Carriers; Petition of US West Communications, Inc. for Forbear-

(Footnote Continued....) 
As with every FCC action, the FCC's Pricing Flexibility Order had its detractors, and the efforts to reverse the decision intensified when the Obama Administration came into power. ${ }^{3}$ The FCC finally acceded to this pressure, and August 2012 the agency released a Report and Order which found that its "existing collocation triggers are a poor proxy for the presence of competition sufficient to constrain special access prices or deter anticompetitive practices throughout an MSA." " Given this change of heart, the Commission took the bold step of suspending, on an "interim" basis, its rules allowing for automatic grants of pricing flexibility for special access services "pending adoption of a new framework that will allow us to ensure that special access prices are fair and competitive in all areas of the country."

The concept of "interim" can take on a bizarre definition in Washington, ${ }^{6}$ so it should come as no surprise that two years after releasing this Report and Order the Commission has yet to release its promised "new framework." While we have no insight as to what might be causing the delay, given the history of the docket, we can surmise that there is a significant debate on how the Commission should define the relevant economic market for high capacity

ance from Regulation As a Dominant Carrier in the Phoenix, Arizona MSA, Fifth Report and Order and Further Notice of Proposed Rulemaking, 14 F.C.C.R. 14,221, 14,231 (Aug. 27, 1999) [hereinafter Pricing Flexibility Order], aff'd sub nom., WorldCom, Inc. v. F.C.C., 238 F.3d 449 (D.C. Cir. 2001).

3 See, e.g., Memorandum from COMPTEL to Susan Crawford and Haley VanDyck 35 (Dec. 19, 2008) (citing studies for the assertion that current prices are too high), available at http://commcns.org/1gw2d1o; In re Ameritech Operating Cos., Letter from Thomas Jones, Partner, Willkie Farr \& Gallagher LLP, on behalf of Time Warner Telecom Inc., to Marlene H. Dortch, Secretary, Fed. Commc'ns Comm'n, WC Docket Nos. 06-125, 05-25 (Jan. 15, 2008), available at http://commcns.org/1pcev1R; In re Special Access Rates for Price Cap Local Exchange Carriers, Comments of the Ad Hoc Telecommunications Users Committee: L.L. Selwyn et al., Special Access Overpricing and the US Economy: How Unchecked RBOC Market Power Is Costing US Jobs and Impairing US Competitiveness, CC Docket No. 05-25 app. 1 (Aug. 8, 2007), available at http://commcns.org/1jVNfT6; PLI: Panelists See Full Telecom Policy Plate in 2009 As FCC Adjusts to New Leadership, Administration, TeleCOMM. ReP. (Jan. 1, 2009) (quoting Sprint Nextel Corp. Chief Executive Officer Dan Hesse's call for the Obama administration to push for an overhaul of the "broken" special access regime, because it is "thwarting the deployment of broadband services"); see also Sprint Nextel Corp., Special Access Pricing, Written Ex Parte Presentation, W.C. Docket No. 05-25, at 60 (Oct. 5, 2007) [hereinafter Sprint Written Ex Parte Presentation], available at http://commcns.org/SHoyi0; PETER BluHM \& ROBERT LOUBE, NAT'L Regulatory Research Inst., Competitive Issues in Special Access Markets (rev. ed. 2009), available at $\mathrm{http}: / /$ commcns.org/RupMvF.

4 Special Access Order, supra note 1, at 10,560.

5 Id.

6 Office of the Fed. Register, A Guide to the Rulemaking Process 9, available at http://commcns.org/1hrXkSe (last visited Feb. 20, 2014). 
circuits for purposes of this new competitive analysis. ${ }^{7}$ For example, many suppliers of special access argue that the market for high capacity circuits should be national. ${ }^{8}$ In contrast, proponents of price regulation for high capacity circuits (generally, purchasers of high capacity circuits) argue for narrow market definitions, such as a building or cell tower. ${ }^{9}$ Other studies propose

7 George S. Ford \& Lawrence J. Spiwak, The Need for Better Analysis of High Capacity Services, 28 J. MARShall J. COMPUTER \& INFO. L. 343, 381-82 (2011) (noting that "the central problem of market definition derives from the confusion between the geographic market for purposes of economic analysis (e.g., HHI calculations) and the administrative market for purposes of regulating or deregulating prices"); see also George S. Ford \& Lawrence J. Spiwak, Set It and Forget It? Market Power and the Consequences of Premature Deregulation in Telecommunications Markets, PHX. CENTER POL'y PAPER No. 18 (2003), available at http://commens.org/1nNCArU, reprinted in 1 N.Y.U. J.L. \& BUS. 675 (2005).

8 See, e.g., In re Petition of AT\&T Inc. for Forbearance under 47 U.S.C. $§ 160$ (c) from Title II and Computer Inquiry Rules with Respect to Its Broadband Services, July 23, 2008 Petition of AT\&T, WC Docket No. 06-125, at 5 ("[B]broadband competition is national in scope and is not limited to . . . the territory of any specific BOC."); In re Petition of the Verizon Telephone Companies for Forbearance Under 47 U.S.C. § 160(c) From Title II and Computer Inquiry Rules with Respect to Their Broadband Services, March 10, 2004 Reply Comments of Verizon, WC Docket No. 04-440, at 18 ("[I]t is appropriate for the Commission to focus on national data, and that is all the more true given that national patterns with respect to broadband availability and competition hold true throughout our service areas. Therefore, reliance on national data in the [sic] context is justified.").

9 See infra note 25. 
multiple definitions,${ }^{10}$ meanwhile others simply choose to avoid the issue altogether. $^{11}$

Much of the disagreements on market definition stem from the fact that there are effectively two types of market definition for purposes of regulating high capacity services. First, there is the "economic" market, whose boundaries are determined using the standard economic approach. ${ }^{12}$ According Kaserman and Mayo, the "economic market":

[I]nvolves identification of a group of buyers and a corresponding group of sellers whose purchase and output decisions determine the equilibrium price. Moreover, these groups must be delineated across both geographic and product space. In other words, market definition requires the identification of both geographic and product boundaries that separate buyers and sellers whose actions influence price from buyers and sellers whose actions do not influence price. The market

10 For example, the NRRI fails to define the relevant economic geographic market. At first, the NRRI Study claims to "estimate HHI for each MSA." BLUHM \& LouBE, supra note 3, at 40 . However, on the next page, the authors calculate an HHI for the "nation" and then "by city." Id. at 41 . The authors also observe that "there is considerable geographic variation from city to city" and that the "level of competition varies by location." Id. at 46, 79. Finally, the authors recommend that the FCC "adopt a finer (more granular) [geographic] scale in making decisions about the competitiveness of special access markets." Id. at 91 . In so doing, the authors recommend that regulators consider the possibility that markets for high capacity services may be a "building" or "city block[]," or perhaps requiring GIS software to measure geographic market boundaries. Id. at 88, 93-94. Not all of these options can simultaneously be legitimate definitions of the "geographic market," and without such a defined market, there can be no meaningful calculation of market concentration. While most of the calculations of the HHI in the NRRI Study are at high level of aggregation (city, MSA, or nation), the authors suggest throughout the Report that Special Access markets are in fact very small. The narrow geographic markets are further stressed, with the authors stating, "[g]eographic differences in concentration can identify particular areas where existing policies are succeeding or failing, and that in turn can suggest policy refinements," or "[g]eographic price differences can identify areas where competition is sharpest and can lead to more effective regulatory policy." Id. at 86 . Furthermore, they argue that "finer" market definitions "could more accurately identify the boundaries of special access competition." Id. at 91 .

11 The Government Accountability Office ("GAO") in particular avoids the term "market" altogether, using "area" in its place. See generally U.S. Gov'T ACCOUNTABILITY OFFice, GAO-07-80, TelecommunicAtions: FCC NeEdS to Improve ItS Ability to MoniTOR AND Determine the EXTENT of COMPETITION in DedicAted ACCESS SERVices (2006) [hereinafter GAO REPORT (GAO-07-80)], available at http://commcns.org/1nNCIaY.

12 Robert G. Harris \& Thomas M. Jorde, Antitrust Market Definition: An Integrated Approach, 72 CALIF. L. REV. 3, 5-6 (1984). 
definition exercise is one of the (if not the) most important aspects of many antitrust cases .... ${ }^{13}$

Definition of the economic market involves clear delineation of both the product and geographic boundaries of exchange. Only after such delineation can one compute a concentration index and then make claims about the presence or lack thereof of market power.

In contrast, the "administrative" market relates to the application or removal of regulatory rules. ${ }^{14}$ An administrative market may contain many economic markets, or may be a subset of an economic market (for instance, special treatment for the poor or handicapped within an economic market). Administrative markets are not bound by the criteria for defining an economic market. ${ }^{15}$ Delineation of the administrative market relates to minimizing the cost or maximizing the benefits of a particular regulatory regime.

The distinction between economic and administrative markets is plain in the FCC's Pricing Flexibility Order, ${ }^{16}$ where the administrative market was selected as the Metropolitan Statistical Area or "MSA." In that decision, the FCC acknowledged that economic markets are likely smaller than the MSA, but chose the MSA as the geographic scope to which regulatory decisions would apply. ${ }^{18}$ This decision was based largely on administrative concerns. As stated in the Order, "the geographic area that . . . should [be] use[d] for purposes of reviewing requests for pricing flexibility" should be defined "narrowly enough so that the competitive conditions within each area are reasonably similar, yet broadly enough to be administratively workable." ${ }^{19}$ Plainly, the agency never defined the economic market to be the $\mathrm{MSA}^{20}$ and recognized that the MSA consists of many economic markets. The D.C. Circuit upheld this choice. ${ }^{21}$ Alternative proposals to grant pricing flexibility at the wire cen-

13 David L. Kaserman \& John W. Mayo, Government And Business: The ECONOMICS OF ANTITRUST AND REgULATION 111 (Daryl Fox et al. eds., 1995) (emphasis in original).

14 Pricing Flexibility Order, supra note 2, at 14,259; see also WorldCom, Inc. v. F.C.C., 238 F.3d 449, 461 (D.C. Cir. 2001) (discussing the FCC's decision to set the geographic bounding of the market so as to administrative workability).

15 Pricing Flexibility Order, supra note 2, at 14,259 (noting the importance of defining geographic areas "broadly enough to be administratively workable").

16 See generally id.

17 Id. at 14,260; WorldCom, 238 F.3d at 461.

18 Pricing Flexibility Order, supra note 2, at 14,259.

19 Id.

20 Id. at 14,260 (limiting the MSA to functioning as a tool for measuring the extent of competition).

21 WorldCom, 238 F.3d at 461. 
ter level, for example, are also based on administrative convenience rather than a formal geographic market definition. ${ }^{22}$

While there are two distinct markets relevant to the price regulation of high capacity services (i.e., administrative and economic), the economic analysis of competition for high capacity services should focus on the economic market, not the administrative market. Economic analysis does offer insight on the selection of administrative markets, and the competitive and administrative analyses are related; however, the objective functions differ between the two markets requiring disparate conceptual frameworks. ${ }^{23}$ It is important for proposals and analyses to distinguish which market is being analyzed, so the relevant economic models are properly selected.

We recognize that there is a dispute about the geographic scope of the economic market. Consequently, in this article we choose sides so as to trace out the theoretical implications of market definition. Assuming arguendo that the proponents of price regulation of high capacity circuits are correct in their argument that the market for high capacity circuits is geographically narrow, ${ }^{24}$ we get a surprising and highly policy-relevant result: price regulation of high capacity circuits would necessarily reduce economic welfare and likely reduce investment in new broadband facilities. There are in fact no trade-offs to consider and the extent of competition (or monopoly) essentially plays no role in the welfare analysis of price regulation for high capacity services. That is, even if high capacity services are provided by a monopolist, price regulation offers no increase in economic welfare.

We obtain this result because if the market for high capacity circuits is regarded as a "particular customer's location" 25 served by a monopoly provider, then high capacity services constitute a "bilateral" monopoly—i.e., a market in which there is only one seller and one buyer (with perhaps unequal bargaining power). ${ }^{26}$ The welfare analysis in this setting is nothing like the standard, text-

22 BLuHM \& LOUBE, supra note 3, at 93-94.

23 Compare Pricing Flexibility Order, supra note 2, at 14,259 (including an administrative oversight as a factor in defining the scope of the market), with KASERMAN \& MAYO, supra note 13, at 111 (defining market as requiring the identification of "geographic and product boundaries that separate buyers and sellers whose actions influence from price" from those whose actions do not).

24 The Need for Better Analysis of High Capacity Services, supra note 7, at 383.

25 In re Verizon Communications Inc. and MCI. Inc., Applications for Approval of Transfer of Control, Memorandum Opinion and Order, 20 F.C.C.R 18,433, 18,449 (Nov. 17, 2005).

26 Glossary of Statistical Terms: Bilateral Monopoly/Oligopoly, OECD, $\mathrm{http}$ //commcns.org/1mvfIxZ (last visited Mar. 1, 2014) ("A bilateral monopoly/oligopoly is a situation where there is a single (or few) buyer(s) or seller(s) of a given product in a mar-

(Footnote Continued....) 
book case of monopoly, where the monopolist seeks to raise price by restricting output. In a bilateral monopoly where one item is exchanged, there is no deadweight loss of monopoly, and the seller cannot reduce output to raise price and profits. Each circuit transaction is unique, and is either sold or left fallow, because there can be no arbitrage in location-specific markets. In such a setting, granting a seller pricing flexibility will result in welfare maximizing transactions because the monopoly seller does not have the incentive to restrict output. Price regulation in this scenario (typically) reduces the quantity of transactions and (always) reduces economic welfare by either forcing welfarereducing transactions or blocking welfare-improving transactions. Accordingly, if the underlying assumptions regarding market definition set forth by proponents of price regulation for high capacity services are correct, then a policymaker interested in maximizing economic welfare should seek to expand, not contract, pricing flexibility for these services.

Our findings are significant because if markets are, in fact, geographically narrow, then many of the traditional arguments for price regulation of high capacity circuits are off point. For example, in a bilateral monopoly setting, regulation reduces welfare even under monopoly supply. Thus, the debate over whether the market is monopolistic or competitive is irrelevant. Similarly, rate of return calculations made from regulatory account data (i.e., the FCC's ARMIS data), which are of dubious merit in any case,${ }^{27}$ are irrelevant since regulation in such a setting unambiguously reduces welfare irrespective of the effect on returns. ${ }^{28}$ Finally, comparisons of prices across regulated and deregulated areas say little to nothing about whether regulation improves welfare, since regulation is not welfare improving.

If the proponents of regulation are correct in their assertion that markets are "location specific," then we must conclude that much of the debate over pricing flexibility is not a debate about economic welfare or a new "national broadband strategy," but rather a squabble over the distribution of rents between buyer and seller. ${ }^{29}$ High capacity circuits are in fact sold from one busi-

ket. The level of concentration in the sale of purchase of the product results in a mutual interdependence between the seller(s) and buyer(s).").

27 The Need for Better Analysis of High Capacity Services, supra note 7, at 345.

28 For examples of studies that try to use ARMIS data to calculate rates of return, see the studies put out by the National Research Institute and the Free Press. See, e.g., BLuHM \& Loube, supra note 3, at 93-94; S. Derek Turner, Free Press, Dismantling Digital DeREgUlation: TOWARD a NATIONAL BROAdBAND Strategy 57-59 (2009) available at http://commens.org/1h6M2Zh.

29 As Cass Sunstein-President Obama's former "regulatory czar"-once observed, "the strongest arguments for cost-benefit balancing are based not only on neoclassical eco-

(Footnote Continued....) 
ness to another (and usually, from one telecom provider to another). While shifting the gains from trade from one firm to another may seem innocuous to some, such shifts have welfare impacts in the bilateral monopoly context, and it is the role of a regulatory cost-benefit analysis to maximize overall welfare and not simply maximize the profits of one industry segment. Our analysis of the market for high capacity circuits, based on the arguments of regulatory proponents, indicates that it is price regulation, not monopoly, which creates a deadweight loss.

Importantly, our conclusions hinge on a particular view of high capacity services, but this view is based on the characterizations of those pushing for heightened regulation of the sector. This analysis is not comprehensive, as we ignore some strategic behaviors many-including us in our prior work ${ }^{30}$ claim are prevalent. That said, price regulation is probably a poor solution to such strategic behavior even if it exists, given the difficulty of implementing a solution that is, on net, beneficial. "Effective" regulation is an elusive goal. Finally, we make no claim about the overall performance of the market. Whether high capacity services markets are competitive or not is beyond the scope of this article, although we believe that the available evidence is insufficient to reach a conclusion on that point. ${ }^{31}$ Our goal in this article is simplewhat are the expected welfare effects of price regulation if high capacity circuits are sold by a monopolist in very narrow markets? The answer is "not good."

In Section II below, we present our economic model. To help the reader grasp better that theoretical discussion, we provide a numerical example (or simulation) in Section III. Conclusions are found in Section IV.

\section{The Welfare Effects of Price Regulating High Capacity Circuits}

Consistent with prior research, it is our view that all regulation should be subject to a cost-benefit analysis that focuses upon the welfare effects of that regulation and tries to account for the administrative burdens and unintended consequences of intervention. In this Section, we analyze the welfare effects

nomics, but also on an understanding of human cognition, on democratic considerations, and on an assessment of the real-world record of such balancing," CASS SUNSTEIN, THE Cost-Benefit State: The Future of Regulatory Protection 9 (2002). Sunstein argued that using cost-benefit analysis will stop interests groups from "fending off desirable regulation or pressing for regulation when argument on [their] behalf is fragile." Id.

30 See T. Randolph Beard et al., Quantity-Discount Contracts As a Barrier to Entry, PhX. Center Pol'y PAPer No. 20, at 2-5 (2004), available at http://commcns.org/1 raO66q.

31 The Need for Better Analysis of High Capacity Services, supra note 7, at 344. 
of subjecting to price regulation a monopoly provider of point-to-point high capacity circuits.

We recognize that many might regard our initial assumption of monopoly and narrow markets as dashing headlong into a minefield. For well over a decade, parties have debated whether the market for high capacity circuits is competitive or not, as well as the type of proxies or "triggers" that might be used to determine whether the market is competitive or contestable. In addition, the geographic scope of regulation (and later de-regulation) has been heavily debated, with many asserting that the geographic market for these services is far more granular than the FCC's MSA-wide approach.

Our approach to analyzing this problem takes a side in that we adopt the arguments of those calling for more, not less regulation. We seek an answer to one very specific, yet highly illuminating question: if the relevant geographic market for high capacity services is a highly location-specific point-to-point market, and if there were only a monopoly provider of such circuits, then would price regulation advance economic welfare? The analysis in this Section shows that the answer to this question is surprisingly "No."

\section{A. Two Key Assumptions: Point-to-Point Geographic Markets and Monopoly Source of Supply}

The core part of our welfare analysis is to assume that high capacity services are sold by monopoly providers in highly granular, point-to-point geographic markets. In this Part II.A, we describe the basis and utility of proceeding with these assumptions.

The point-to-point assumption of our analysis is not altogether a radical approach, as a common theme in the criticisms of the FCC's approach to deregulation of high capacity services regards the choice to deregulate at the level of MSA. Critics claim that the MSA is too large a collection of the narrower geographic markets, since competition may differ considerably across the component markets. ${ }^{32}$ In fact, many have contended that the geographic market is simply the connection between any two points. ${ }^{33}$ The geographic scope

\footnotetext{
32 Bluhm \& LouBE, supra note 3, at 91.

33 In re Applications of NYNEX Corporation, Transferor, and Bell Atlantic Corporation, Transferee, for Consent to Transfer Control of NYNEX Corporation and Its Subsidiaries, Memorandum Opinion and Order, 12 F.C.C.R. 19,985, 20,015-17 (Aug. 14, 1997); see also BellSouth Transport - Special Access (SPA) Products, AT\&T, http://commens.org/1nruXJk (last visited Mar. 1, 2014); Point-to-Point Services, CInCIN-
} 
of the market is, as some argue, the end user's location. For example, the wireless carrier Sprint, a vocal advocate for the regulation of Special Access services, observes "that, as a theoretical matter, the relevant geographic market for loops and transport is the geographic area served by a route connecting the two points that a purchaser seeks to link with the dedicated facility (e.g., customer premises and central office, or central office and access tandem). ${ }^{\prime 34}$ Others echo the sentiment, claiming that the geographic market for high capacity services is "route connecting the two points that a purchaser seeks to link with the dedicated facility" or "a given location or for a given facility." ${ }^{35}$ The FCC has reached a similar conclusion, concluding that "the relevant geo-

NATI BELL, http://commcns.org/1onyPNF (last visited Mar. 1, 2014).

34 Sprint Written Ex Parte Presentation, supra note 3, at 59.

35 In re International Comparison and Consumer Survey Requirements in the Broadband Data Improvement Act, A National Broadband Plan for Our Future, Inquiry Concerning the Deployment of Advanced Telecommunications Capability to All Americans in a Reasonable and Timely Fashion, and Possible Steps to Accelerate Such Deployment Pursuant to Section 706 of the Telecommunications Act of 1996, As Amended by the Broadband Data Improvement Act, Comments of Cavalier Telephone, LLC to NBP Public Notice \#1, GN Docket Nos. 09-47, 09-51, 09-137, at 5 (Nov. 5, 2009) ("Special access facilities are generally dedicated circuits that connect an end-user facility, such as a building in a business district, to another facility or POP, without routing through a local exchange switch."); In re Special Access Rates for Price Cap Local Exchange Carriers; AT\&T Corp. Petition for Rulemaking to Reform Regulation of Incumbent Local Exchange Carrier Rates for Interstate Special Access Services, Comments of Sprint Nextel Corporation, W.C. Docket No. 05-25, at 15 (Aug. 8, 2007) ("The relevant geographic market for special access, therefore, is the geographic area served by a route connecting the two points that a purchaser seeks to link with the dedicated facility (e.g., cell site and central office, or central office and access tandem)."); Response Testimony of Don J. Wood at 13, In re Joint Application of Verizon Communications, Inc. and MCI, Inc. for Approval of Agreement and Plan of Merger, WUTC Docket No. UT-050814 (Sept. 9, 2005) ("the market also depends on aggregate end user demand at a given location or for a given facility."); Declaration of Ajay Govil on Behalf of XO Communications, LLC at 7, In re Minnesota Public Utilities Inquiry Regarding the Petition of Qwest Corporation, Filed with the Federal Communications Commission, for Forbearance Pursuant to 47 U.S.C. Section 160(c) in the Minneapolis-St. Paul Minnesota Metropolitan Statistical Area, MPUC Docket No. P421/CI-07-661 (Aug. 16,2007 ) ("A loop facility is dedicated to the use of one customer or in limited instances a very small group of customers."); Competitive Local Exchange Carriers (CLEC), VERIZON, http://commens.org/1 raOguF (last visited Mar. 1, 2014) ("As demand in network capacity continues to increase to support high bandwidth services and when bandwidth requirements between two locations are very large, Optical Wave Service may be your preferred solution for interconnectivity."); In re Review of the Section 251 Unbundling Obligations of Incumbent Local Exchange Carriers, Implementation of the Local Competition Provisions of the Telecommunications Act of 1996, Deployment of Wireline Services Offering Advanced Telecommunications Capability, Report and Order on Remand and Further Notice of Proposed Rulemaking, 18 F.C.C.R. 16,978, 17,175 (Aug. 21, 2003) ("impairment analysis should be applied on a customer-by-customer location basis."). 
graphic market for wholesale special access services is a particular customer's location . .." In In its Pricing Flexibility Order, the FCC explicitly embraced the legitimacy of a more narrow market definition, admitting it "might produce a more finely-tuned picture of competitive conditions . .." ${ }^{37}$ Likewise, the agency also observed that it would not delay "regulatory relief until access customers have a competitive alternative for access to every end user," again suggesting a view of a more narrow market definition than the MSA. ${ }^{38}$

In its recent study, NRRI echoed the sentiment and "recommend[ed] that the FCC adopt a finer (more granular) scale in making decisions about the competitiveness of special access markets. [NRRI's] recommendation applie[d] with particular force to channel terminations." ${ }^{39}$ The study stated that the FCC, in one of its earlier decisions, had "simply and unambiguously" defined the geographic market for high capacity services as a "particular customer's location." ${ }^{40}$ As alternatives to MSA level flexibility, NRRI proposed a geographic unit of measurement of a city block, and possibly using even GIS mapping to set narrow market boundaries for the computation of market share statistics. ${ }^{41}$

Whether the actual geographic (economic) market for high capacity services is a "particular customer's location" is debatable, though widely accepted. As such, we do not challenge this definition of the geographic market in this article; rather, we base our modeling assumptions on it. Such an approach seems reasonable, since this definition of the "market" is consistent with the position of those proposing more strict regulation of high capacity services. As a result, we study the welfare impact of price regulation in a geographic market defined to be a particular customer location.

The other key assumption of our model is that point-to-point high capacity circuits are provided by a monopoly. A central feature of the advocacy in favor of stricter regulation focuses upon the purported lack of competition in the provision of high capacity services. For example, the wireless carrier Sprint asserts that for the majority of lower-capacity services, special access customers do not have competitive alternatives to the price cap LECs' offerings. ${ }^{42}$ Likewise, the wireless carrier T-Mobile, another advocate for regulating Spe-

36 In re Verizon Communications Inc. and MCI, Inc. Applications for Approval of Transfer of Control, Memorandum Opinion and Order, 20 F.C.C.R. 18,433, 18,446 (Nov. 17, 2005).

37 Pricing Flexibility Order, supra note 2, at 14,260.

38 Id. at 14,298.

39 Bluhm \& Loube, supra note 3, at 91.

$40 \quad$ Id. at 92.

41 Id. at 94

42 Sprint Written Ex Parte Presentation, supra note 3, at 18. 
cial Access prices, claims that price cap ILECs are the "sole source" of high capacity services at nearly all of its cell sites. ${ }^{43}$ The GAO study on high capacity services summarizes data showing that only $6 \%$ of buildings with DS1 or greater demand have a competitive alternative, though this number was much higher for locations with DS3 or higher demand levels. ${ }^{44}$ According to NRRI's study, "ILECs still have strong market power in most geographic areas, particularly for channel terminations and DS- 1 services." ${ }^{35}$ In both of these two studies, however, the authors explicitly recognized that the extent of competitive alternatives for high capacity services is exceedingly difficult to measure. There are no centralized databases of competitive alternatives, and the "absence of evidence" is not "evidence of absence." A more rigorous analysis of high capacity services than has occurred to date is required to understand fully the costs and benefits of regulatory intervention.

We suspect the debate over the extent of competition for high capacity circuits will continue unimpeded, but it is beyond the scope of this article to reject or embrace the legitimacy of the monopoly or competitive claims ${ }^{46}$ Indeed, we believe that our welfare analysis of subjecting a monopoly supplier to price regulation is a liberating approach, because it shows that debates over market structure and actual versus potential competition are largely irrelevant. Simply stated, if price regulation fails to improve welfare, even if one assumes a monopoly, then the prospects for beneficial regulation in more competitive structures are exceedingly grim.

We turn now to the evaluation of the effects of regulation under the conditions outlined above-customer-specific markets and monopoly supply. Our analysis reveals that this combination of assumptions introduces an interesting wrinkle to the analysis of regulation and pricing flexibility. In particular, if the market is a "particular customer's location" as the FCC has concluded in some contexts and as proponents of price regulation appear to argue, then there is only one buyer at each location. ${ }^{47}$ For example, there is only one buyer at a carrier's cell tower. It follows, then, that there is one seller and one buyer, that

\footnotetext{
43 In re Special Access Rates for Price Cap Local Exchange Carriers, Comments of TMobile USA, Inc., WC Docket No. 05-25, at 6 (Aug. 8, 2007), available at http://commens.org/1waMnyb.

44 GAO REPORT (GAO-07-80), supra note 11, at 19.

45 BLUHM \& LOUBE, supra note 3 , at iii.

46 The Need for Better Analysis of High Capacity Services, supra note 7, at 345.

47 In re Verizon Communications Inc. and MCI, Inc. Applications for Approval of Transfer of Control, Memorandum Opinion and Order, 20 F.C.C.R. 18,433, 18,449 (Nov. 17, 2005).
} 
is, there is a "bilateral" monopoly. ${ }^{48}$ Bilateral monopoly does not pre-suppose equal bargaining power, and such power may be strongly asymmetrical. ${ }^{49}$ Nevertheless, this bilateral monopoly provides an important caveat to the ordinary analysis of deregulation and its welfare consequences.

\section{B. Regulation and Bilateral Monopoly}

We consider the following stylized, yet practically relevant scenario. Suppose that a potential seller could choose to install equipment at a certain location, which is differentiated from all other locations (to some degree) by space. This location could be considered a wire center, tandem, or other network node. ${ }^{50}$ Radiating from this office are numerous potential "branches," which are also spatially unique and have non-zero costs. For present purposes, we can take these to represent channel terminations, a stylized arrangement illustrated in Figure 1.

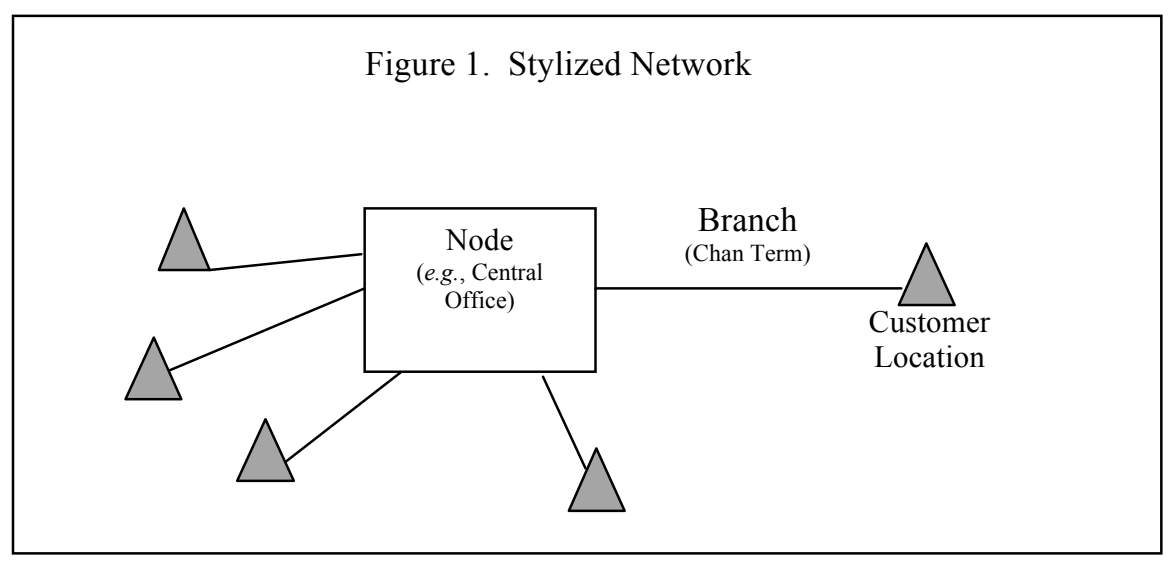

The decision of the firm to locate, or not locate, at this node, as well as whether the firm provides certain branches off the node, involves several considerations. First, consistent with the arguments of regulatory proponents, the seller, $S$, has a small "spatial monopoly" in the sense that no other seller would

48 See generally Roger D. Blair et al., A Pedagogical Treatment of Bilateral Monopoly, 55 S. ECON. J. 831 (1989) (analyzing the bilateral monopoly).

49 Id. at 836-37.

50 Wire centers and tandems are points of traffic aggregation in the telecommunications network. Local distribution plant (e.g., loops) connects to the wire center, and wire centers are connected either directly or through tandems. 
be able to precisely duplicate that location. Second, because of the spatial uniqueness of the branches, there exists a countervailing power on the part of potential buyers of these connections. In particular, we will imagine that, for a given circuit, there is only one potential buyer. Finally, there may well be some substantial sunk cost to the seller arising from installing the necessary capital equipment at this node. We denote these sunk costs to the seller by $K$ at the node, and deal with branch costs later.

We first focus on the transactions involving the transfer of control of a branch from seller to buyer. Clearly, both the node decision and branch transactions are motivated by potential returns to the required investments, which returns depend on the form of any regulation of connection prices that may apply, as well as the valuations of these services by buyers, along with variable costs. Formally, at any given node, there is a "large" collection of $i$ branches, each of which are bilateral monopoly markets containing the potential seller, denoted $S$, and a potential buyer at branch $i$, denoted $B_{i}$. The branch is a single, indivisible good, denoted $X_{i}$. Our interest focuses on those situations in which the use of $X_{i}$ may be transferred from $S$ to $B_{i}$, and the prices under which this transfer might occur.

The assumption of a single, indivisible good is for expositional purposes alone. At any given location, multiple circuits may be exchanged (for example, a few T1s). This "divisibility" of the circuits does not change the basic conclusion of the analysis. The only requirements for our results, as far as this issue is concerned, are that (1) there exists bilateral monopoly and, (2) there is freedom of pricing/contract terms between buyer and seller. In the case where several smaller circuits could do the job of a larger one, the final transaction will transfer precisely that collection of elements which generates the greatest gains from trade, since this result provides the largest pool of benefits over which the buyer and seller can negotiate. In other words, it makes no material difference whether what is being sold is literally a single, indivisible object or not.

Assume only one unit of $X$ is transferred (i.e., a circuit). Let $b_{i}$ be the potential buyer's reservation price (valuation) of $X_{i}$, and let $s_{i}$ be the seller's reservation value of $X_{i}$. Let $c_{i}$ be the cost of the transfer of the use of $X_{i}$ from $S$ to $B_{i}$, where $c_{i}>0$ (the transfer is not free). We assume that these values are unknown to the regulator who must, for practical reasons, establish a single statutory price for elements $X_{i}$, where $i=1,2, \ldots N$.

For any given branch, the potential gains from trade are just $b_{i}-s_{i}-c_{i}$, and, when those gains are positive, one expects that negotiation between the parties will result in a transfer. For example, if the buyer's reservation value is $\$ 100$, the seller's reservation value $\$ 50$, and the cost of transfer is $\$ 10$, then the gains from trade are $\$ 100-\$ 50-\$ 10=\$ 40$. In the absence of some barrier to trade and in the absence of price regulation, we will see transfers in all markets from 
which positive gains are the result. There is no reason not to trade when there are gains from it, regardless of market power on behalf of either buyer or seller. It may be the case the seller captures most of the gains from trade, or maybe the buyer captures the bulk of the gains, but this distribution is irrelevant to measuring total welfare. The trade occurs, and society captures the gains from trade.

To see the uniqueness of this case, we note the following. First, in the absence of regulation, trade occurs whenever $b_{i}-s_{i}-c_{i}>0$. All gains from trade are realized by the parties, and welfare (in a partial equilibrium sense) is maximized. In contrast, under any regulatory mechanism that produces a single price $r^{*}$, even when that price is judiciously selected to maximize welfare (which, in practice, is never the case), some beneficial sales will not occur and some welfare-reducing sales will occur. The implication is that there will be lower welfare, fewer transactions, and lower investment. ${ }^{51}$

For example, if the seller is not required by regulation to complete every transaction desired by the buyer, then regulation reduces the number of transactions and welfare. Consider the following scenario. First, let $r^{*}<b_{i}$, so the buyer wants to exchange. Second, let $r^{*}<s_{i}+c_{i}$, where the regulated price is set below cost. Third, let $b_{i}>s_{i}+c_{i}$, implying a deal outside of regulation could be reached. In this scenario, the seller refuses to transact, even though the transaction would occur and generate surplus in the absence of regulation.

Assume now that a seller is forced to make any exchange that a buyer desires. Sales will occur only when $r^{*}<b_{i}$. In instances where $s_{i}+c_{i}>b_{i}$, the resulting transfer is value destroying in that the price is less than the cost of provision, even though the buyer wants to proceed. ${ }^{52}$ Under a mandate to sell, therefore, there may be sales that are welfare reducing. There may also be sales that do not occur, but should. Suppose, for example, that $s_{i}+c_{i}<b_{i}$ (both parties want to exchange), but $r^{*}>b_{i}$ (the regulated price exceeds the buyer's reservation price). In this case, the regulated price is too high for this given pairing to occur, even though both the buyer and seller would wish it to happen. $^{53}$ Again, regulation reduces welfare, even if, at very low regulated prices, transactions may increase. We note that forcing the seller to make unprofitable

\footnotetext{
51 These conclusions are based on the assumption that regulation induces some inefficient transactions, else regulation has no effect at all.

52 For example, let $b_{i}=\$ 60, s_{i}+c_{i}=\$ 70$, and $r^{*}=\$ 50$. No trade would occur absent regulation, but with regulation the gain from trade is -10 (a social loss).

53 For example, let $b_{i}=\$ 60, s_{i}+c_{i}=\$ 50$, and $r^{*}=\$ 70$. The buyer does not wish to make this transaction even though, without regulation, the buyer and seller would be willing to do a deal at a price of, say, $\$ 55$. If there is significant flexibility to reduce prices, then this case will not generally occur even under regulation.
} 
transactions is likely to meet some resistance, such as procedural delays, regulatory squabbles, and so forth. If so, resources are wasted fighting over transactions.

This analysis reveals that unless there is some barrier to trade, in the absence of regulation the expectation should be for buyer and seller to implement first-best, welfare optimal transactions, even under monopoly. It is true that one party may prefer a lower or higher price, but this preference is simply a squabble over rents and has no effect on total economic welfare. The point is made plain by Blair, Kaserman and Romano in their seminal work on Bilateral Monopoly:

$[\mathrm{N}]$ egotiation must lead to the maximization of joint profits if the firms are to be on the contract curve. $* * *$ Regardless of how it is determined, it is important to note that the price of the ... good does not serve as a rationing device. Instead, it is merely a means of dividing the joint profits. ${ }^{54}$

In contrast, under price regulation that establishes either a single price, or a price cap, there can be market pairings under which inefficient transactions occur, or efficient ones are ruled out. ${ }^{55}$ In the remaining cases, in which private interests align with the regulated price, regulation provides no social benefit, since the transaction would occur anyway under negotiation. ${ }^{56}$ Regulation merely forces a transfer from seller to buyer, but the gain to the buyer is equal to the loss to the seller. Consequently, regulation only reduces the number of transactions and is, by definition, welfare reducing. There is no net gain from regulation.

This analysis is exceedingly important to the debate over special access pricing flexibility and is unique in some ways. Ordinarily, regulatory intervention is undertaken to provide something that the unregulated market process does not. ${ }^{57}$ With regard to price regulation, the standard view is that judicious price regulation can eliminate welfare losses ${ }^{58}$ but this view is based on a variable quantities framework where homogeneous units are sold to atomistic consumers in a centralized marketplace. Whether regulation successfully does so in practice is debatable, but that debate is irrelevant here.$^{59}$ In this analysis, we

54 Blair, supra note 48, at 839.

55 Kenneth E. Train, Optimal Regulation: The Economic Theory of Natural MONOPOLY 19 (1991).

56 Blair, supra note 48 , at 834-35.

57 TRAIN, supra note 55, at 1.

58 Id. at 2-3.

59 See generally George J. Stigler \& Claire Friedland, What Can Regulators Regulate? The Case of Electricity, 5 J. L. \& Econ. 1 (1962); Thomas W. Hazlett \& Matthew L. 
show, under market conditions consistent with pro-regulation advocacy and some FCC decisions, that price regulation can be expected to reduce economic welfare even when it is well intentioned and administratively costless to implement. Consequently, price regulation for high capacity services reasonably described in this manner should be avoided. In fact, at a time when many claim that flexibility should be reduced, ${ }^{60}$ this analysis suggests that pricing flexibility should be extended to the entire class of offerings that plausibly meet the "particular customer's location" view of geographic market definition.

Additionally, while increased regulation is often causally linked to reduced investment and welfare, neither theory nor empirics generally support this causal relationship. ${ }^{61}$ Certainly, regulation done poorly, as is often the case, can reduce investment levels, output, and welfare..$^{62}$ Theoretically, though, regulation may increase investment and welfare; it depends on the nature of the regulation. The Averch-Johnson effect, for example, implies that firms will overinvest in capital equipment in order to increase the absolute level of profits. ${ }^{63}$ Regulation, then, increases investment, but to inefficient levels (and possibly inefficient capital-to-labor ratios). ${ }^{64}$ Price cap regulation intends to resolve this defect, thereby increasing efficiency and welfare. ${ }^{65}$ However, to do so, the regulation reduces investment. ${ }^{66}$

In the standard, variable quantities, central market analysis typical of theory and policy debates, regulation has an unambiguous relationship to welfare, transactions, or investment. ${ }^{67}$ Contrariwise, in the presence of bilateral monopoly and a fixed quantity, regulation unambiguously reduces welfare and the number of transactions ${ }^{68}$ which reasonably implies a reduction in the investment level. In this regard, "special" access may, in fact, be truly special.

Spitzer, Public Policy Toward Cable Television: The Economics of Rate Controls (1997).

60 GAO REPORT (GAO-07-80), supra note 11, at 19, 41-42; see also Special Access Order, supra note 1 , at 10,558-63, 10,572.

61 For a useful review of the theory, see chapters 1 and 3 and the appendix on price caps in Kenneth Train's book, Optimal Regulation. See Train, supra note 55, at 19-67, 95113, 317 app.

62 Id. at $20-21$

63 Id. at 61 .

64 Id. at 52

65 Gregory J. Vogt, Cap Sized: How the Promise of the Price Cap Voyage to Competition Was Lost in a Sea of Good Intentions, 51 FED. CoMM. L.J. 349, 365 (Mar. 1, 1999).

66 Id. at 366.

67 Lawrence J. Spiwak, Sending the Wrong Signals on Special Access Deregulation, @ lawandeconomics, Phx. Center L. \& Econ. Blog (June 22, 2012), http://commens.org/1ilU6Qi.

68 Id. 


\section{The Node Decision}

In the prior analysis, we ignored the decision about investments in the wire center or other network node to which the branches attached. If the node does not exist and so the investment is incremental, then the expected profits from the sale of branches off the node must be sufficient to cover the node investment $K$. That is, for the node to exist, it must be the case that $\Sigma\left(t_{i}-s_{i}-c_{i}\right)>K$, where $t_{i}$ is the transaction price at branch $i$. The reduction in welfare caused by regulation reduces the expected total profits of the firm at that node. If these total profits are insufficient to cover setup costs $K$, then the node and its associated branches will not exist. The welfare and investment effects could be sizeable in such cases.

It could be argued that all the needed wire centers and nodes already exist and that such investments are sunk, so that the node decision is a bygone. While the argument has some appeal, it is not without its problems. First, if regulators establish a reputation of slashing prices after sunk costs are incurred, then the incentive to incur such costs in the future are attenuated. As a result, network deployment in future periods is reduced and a dynamic inefficiency is realized. Second, there are many cases where the node decision is incremental, both in creating new nodes and in expanding existing nodes. Telecommunications networks are constantly being upgraded, extended and expanded, as the current trend is to push fiber deeper into the network, often creating new nodes (perhaps to avoid data congestion). If the branches of a node are regulated and profits are insufficient to warrant the investment, or fear of price cuts in the future that ignore (or take advantage of) sunk costs, then fewer nodes will exist. ${ }^{69}$ And if investments are recurring, then the "quality" of the node made be reduced, or nodes may be eliminated, if profits are insufficient to warrant continued investments. In the end, the practical relevance of the node decision for policy is an empirical one, and beyond the present scope.

Notably, as much of the debate today regarding broadband deployment is about expanding the availability of high-capacity circuits in rural markets ${ }^{70}$ as it is about regulating existing circuits. Plainly, absent the sufficient subsidies to

\footnotetext{
69 Paul Levine et al., Utility Price Regulation and Time Inconsistency: Comparisons with Monetary Policy, 57 OXford ECON. PAPERS 447, 449 (2005).

70 Lawrence J. Spiwak, The FCC's Special Access Fiasco: No Data and Wrong Policy Questions, @lawandeconomics, Phx. Center L. \& Econ. Blog (Aug. 24, 2012), http://commcns.org/S9KLVd.
} 
make such deployment profitable, creation of new capacity and new circuits will not be served well by price regulation.

\section{Posting Price with Flexibility}

There is evidence, at least for some carriers, that posted prices under flexibility are higher than those under regulation. The NRRI (2009) and GAO (2006) studies are examples, but there are others. ${ }^{71}$ While there are many explanations for these price differences, it is worth observing why this might occur in light of our theoretical framework.

Welfare is largest under pricing flexibility because bargaining is possible, so that all transactions occur that produce gains from trade. If we consider a posted price as a first offer, then from a practical perspective we should expect the posted price to be high. Why? Because for sellers, "negotiating up" is not typically an option. Flexibility, then, only implies downward flexibility if a price is posted. If many buyers are paying less than the posted prices, and there is some evidence to support this practice, then our analysis may explain, in part, the trend in prices.

Another explanation is that the relaxation of regulation has allowed sellers to better exploit their bargaining power. However, this interpretation of the data does not imply a welfare reduction, but merely a transfer between buyers and sellers. We discuss that point in the next section.

\section{E. Dividing the Gains from Trade}

From a theoretical perspective, in this analysis a transaction occurs when there are gains to trade, but how those gains are distributed between buyer and seller is another issue. There are many potential outcomes of the bargaining process. In the Nash Bargaining Solution, the gains will be split equally between buyer and seller; this arises, in part, from the assumption of symmetric bargaining power. ${ }^{72}$ If bargaining strength is not symmetric, then other distributions can occur. ${ }^{73}$

71 In re Verizon Communications Inc. and MCI. Inc., Applications for Approval of Transfer of Control, Memorandum Opinion and Order, 20 F.C.C.R 18,433, 18,449-50 (Nov. 17, 2005).

72 John F. Nash, Jr., Equilibrium Points in n-Person Games, 36 Proc. NAT'L ACAD. SCI. 48, 48-49 (1950); Ken Binmore et al., The Nash Bargaining Solution in Economic Modeling, 17 RAND J. ECON. 176, 186 (1986).

73 Nash, Jr., supra note 72, at 48-49; Binmore, supra note 72, at 186-87. 
In this light, our analysis suggests that much of the debate over pricing flexibility is simply a squabble over the distribution of rents. A review of the pro-regulatory arguments suggests that this distributional issue is prevalent, if not driving. Our analysis shows the profound error in this logic. For every $\$ 1$ in gains transferred by price regulation from seller to buyer, not only does the seller lose $\$ 1$, but there is an additional welfare loss. Making the buyer $\$ 1$ better off makes others more than $\$ 1$ worse off. So, while distributional concerns may be legitimate, the cost of implementing a transfer of wealth from buyer to seller is high, and necessarily higher than the benefits. In other words, the regulator may worry about distribution, but doing something about it is probably too costly.

\section{F. Comparison to the Textbook Monopoly Case}

We recognize that our findings may be surprising and possibly even confusing. Clearly, our claims are not those typical to discussions on regulation, which in the U.S. are consistently motivated by the familiar, textbook variable quantities monopoly framework with atomistic (or many) buyers. ${ }^{74}$ This scenario is not applicable to high capacity services. ${ }^{75}$ It is important to recognize the role that the indivisibility of the objects being traded plays in this analysis, since it is not the "textbook" case of market power.

In the standard treatment, whenever both market power and variable quantities exist, there is always the potential for inefficient equilibria due to the inability of the party with market power to extract surplus from otherwise socially beneficial transactions. Put simply, when only one price is charged and quantities are variable, output is reduced to raise prices and profits, creating welfare losses. Panel A in Figure 2 illustrates this standard, textbook case of monopoly with variable quantities: The monopolist faces demand curve $\mathrm{D}$ and produces the item at marginal cost $\mathrm{MC}$. The welfare maximizing output is $\mathrm{Q}_{\mathrm{C}}$, which is sold at price $\mathrm{P}_{\mathrm{C}}$, where price is equal to marginal cost. This is also the perfectly competitive equilibrium. A profit-maximizing monopolist prefers price $\mathrm{P}_{M}$ and reduces quantity to $\mathrm{Q}_{M}$ to achieve it. The area labeled $T$ is the

\footnotetext{
74 Regulation of Natural Monopoly, BOUNDLESS (Feb. 12, 2014), http://commons.org/1kiPrnc.

75 We applied this variable quantity framework in an econometric analysis of pricing for DS0 circuits in our paper. Set It and Forget It?, supra note 7. These smaller circuits may be more sensibly analyzed in this framework, since they are low priced and low capacity services for which transaction-specific negotiations are unlikely. Id. It seems clear, however, that high capacity circuits to cell towers cannot be evaluated in a variable quantities framework. Id.
} 
transfer from buyers to seller and is equal to profit, and the triangle D is the deadweight loss of monopoly, or the welfare that neither buyer nor seller capture. The area D represents the loss to society of market power, and it is this loss that justifies regulatory intervention.

Here, the monopolist holds back output in order to raise price and increase profits. But, for every $\$ 1$ of higher profits, consumers lose more than $\$ 1$ of surplus. The gain to the monopolist is a transfer from buyer to the seller (rectangular area $\mathrm{T}$ in Panel A), but there is also a deadweight loss of welfare that is uncaptured by any market participant (triangle D in Panel A), since price is set above marginal cost. Consumers lose $\mathrm{T}+\mathrm{D}$, but the monopolist gains only T. At the monopoly price, beneficial trade is possible since buyers are willing to pay more than costs, but such transactions are lost when the monopolist sets a single price to maximize profit. (Importantly and rarely acknowledged is the fact that monopoly is not inefficient, per se; rather, a monopolist charging a uniform price is inefficient. ${ }^{76}$ If the monopolist can charge each buyer its reservation price, then welfare is maximized, though captured completely by the monopolist.)

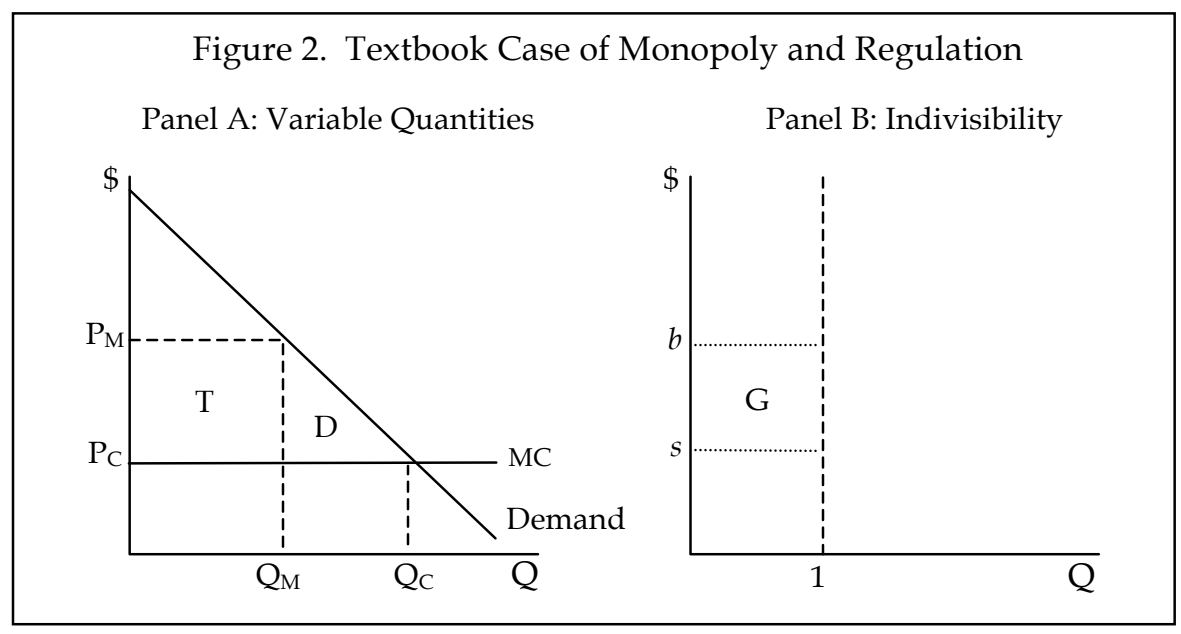

In this textbook case, price regulation aims to reduce the monopolists' price in an effort to capture a portion of this deadweight loss. For every $\$ 1$ reduction in price, more than $\$ 1$ is gained by consumers (a part of $\mathrm{T}$ is transferred to

76 Peter T. Leeson \& Russell S. Sobel, Costly Price Discrimination, 99 ECON. LETTERS 206 (2008). 
buyers, and they also gain a part of D), so regulation makes sense, at least in a naïve, textbook analysis. Of course, regulation is neither costless nor perfect, and these realities must be considered when evaluating intervention in the real world. In many cases, the distortions resulting from regulation exceed any welfare gains from regulatory action since regulators are imperfect and frequently politically motivated. ${ }^{77}$

With bilateral monopoly and variable quantities, the case is more complex, but there is no ex ante assumption that the outcome will be jointly profit maximizing, or otherwise efficient. ${ }^{78}$ But, the failings of the bilateral solution to obtain an efficient outcome largely vanish when there is a single unit of an indivisible good exchanged, such as a channel termination. In general, cooperative bargaining models, such as that of the Nash Bargaining Solution, take Pareto optimality of the solution as an axiom. ${ }^{79}$ So left to themselves, one may assume that the buyer and seller in any given market will, in fact, make a transaction when there are gains from doing so, even if all the gains are captured by one party or the other. In other words, as long as there are gains to trade available, trade will occur in an unregulated environment.

Imagine a case where a circuit exists on a farm where a cell tower has been located. There is no party interested in buying that circuit other than the cell phone carrier; there is only one seller (by assumption), and there is only one circuit. The two parties agree to exchange use of the circuit, or it lays fallow. In this case, the monopolist cannot manipulate price by adjusting quantity, or give up lower valuation buyers to extract rents from the higher valuation buyers as in the variable quantities case. In such bargaining situations, as long as there is a buyer with a greater value for the item than the seller, both seller and

77 See Paul L. Joskow \& Nancy L. Rose, The Effects of Economic Regulation, in 2 HANDBOOK OF INDUSTRIAL ORGANIZATION 1450, 1451, 1454, 1487 (Richard Schmalensee \& Robert Willig eds., 1989). For example, Joskow and Rose assert that:

$[R]$ egulation may introduce political considerations into input choice decisions. This will apply to non-labor inputs as well as labor inputs. For example, utilities may be subject to political pressures to buy local products (e.g., coal), rather than cheaper substitutes from suppliers in other states, to bolster the local economy. Depending on the state, they might also come under pressure to use unionized employees when they otherwise might not, or to sign lavish wage agreements.

Id. at 1490 .

78 F.M. SCherer, Industrial Market Structure and Economic Performance 300 (2d ed. 1980). As observed by Scherer and Ross, "We see that what happens under bilateral monopoly depends in part upon whether the buyer or seller exercises price leadership. Neither of these leadership solutions, however, is consistent with joint profit maximization [and the] joint profit-maximizing quantity might also be achieved if one party can successfully pursue a 'take it or leave it' strategy." Id.

79 Nash, Jr., supra note 72 , at 48-49. 
buyer gain from trade. The profit maximizing solution for both is to find some price at which the trade occurs. Otherwise, money (or welfare) is left on the table.

Panel B illustrates the case we have here. There is but one item to trade, with buyer value $b$ and seller value $s$. If $b>s$, there are gains from trade. At some price between $b$ and $s$, both parties agree to trade and both will gain, and the welfare potential (area $\mathrm{G}$ ) will be realized. If there is no trade, both parties receive nothing and leave the gains unrealized. Of course, the distribution of these gains depends on where the price is set between $b$ and $s$, and this decision depends on the bargaining power of the parties. If the price is set closer to $b$, then the seller gets most of the surplus. If the price is set close to $s$, then the buyer gets most of the surplus. For the Nash Bargaining Solution (symmetric bargaining power), the price is set at the midpoint between $b$ and $s$. But whatever the end price, welfare is maximized by trading.

If the seller has more bargaining power, then the seller will capture more of the gains from trade and price will be closer to $b$ than $s$. In the special access debate, the debate over price regulation appears directed mainly at enforcing a transfer of rents from the ILEC sellers to the buyers. In this bilateral framework, it is easy to see that this is the only possible explanation for dispute. As we have shown, any effort to enforce such a transfer reduces overall welfare, costing society more than $\$ 1$ for every $\$ 1$ transferred. As a result, price regulation of high capacity services, and in particular channel terminations that are more frequently and sensibly characterized as location specific markets, should be avoided (not only in the Top 50 MSAs, but all areas). ${ }^{80}$

Figure 2, Panel A, can be used to provide a rough analogy to the bilateral monopoly case of Figure 2, Panel B. Though an imperfect analogy for a number of reasons, it nevertheless may help with comprehension. In the textbook case of a monopolist selling a homogeneous output to many buyers, the welfare maximizing solution can be obtained under first-degree price discrimination. ${ }^{81}$ That is, the monopolist sells its output to each customer at the customer's reservation price (the highest price the customer is willing to pay). Doing so renders the welfare maximizing quantity $\mathrm{Q}_{\mathrm{C}}$ and there is no dead-

80 The Need for Better Analysis of High Capacity Services, supra note 7, at 345.

81 Dirk Bergemann et al., The Limits of Price Discrimination 2 (Princeton Univ. Econ. Theory Ctr., Research Paper No. 052-2013, May 14, 2013) ("[I]f the monopolist has complete information about the valuation of the buyers, then he can completely segment the market according to true valuations. This results in perfect or first degree price discrimination. The resulting allocation is efficient, but consumer surplus is zero and the producer captures all of the gains from efficient trade."). 
weight loss. However, all surplus is captured by the monopolist. First-degree price discrimination illustrates the idea that it is not monopoly that is inefficient, but monopoly selling at a uniform price. While roughly analogous in that it demonstrates the problem with assuming monopoly is inefficient, per se, there are many differences in this example and the case of bilateral monopoly we consider. First, in the situation we examine, we do not have atomistic buyers and the good sold is heterogeneous. Further, for small purchases, the transactions costs of pulling off perfect price discrimination are likely to offset any increase in profitability. Special access is not a "small" purchase.

\section{Numerical Simulation of the Theory}

We recognize that the implications of the theoretical argument above may be difficult to grasp, particularly given the heavy reliance of policy debates on exceedingly simple economic models of regulation. The idea that regulation necessarily reduces welfare even if regulators are right-minded, informed, and their actions are costless, is a strong claim. When the concepts are difficult, numerical examples often aid comprehension. So we provide a numerical simulation of the theory here, which is essentially a fancy numerical example.

\section{A. Simulation Setup}

Our interest is in the effects of regulation on welfare and the number of transactions in a setting of bilateral monopoly with the exchange of a single good. Since investments are plausibly related to transactions, we can also make some claims about investment levels and regulation. To begin, we assume there are 100 potential branches at some given node, and we will focus only on this node. This setup allows us to determine how many of the branches are served with and without price regulation. Next, we need to assign values of $b_{i}, s_{i}$, and $c_{i}$, so we can decide when transactions will occur and compute the gains from trade. For variety in these values, we generate independent random variables to represent the reservation values for both buyers and sellers $\left(b_{i}\right.$ and $s_{i}$ from above). The average of seller valuation is assumed to be lower than buyer valuation, just so a significant number of transactions occur. These values are randomly generated from the $\chi^{2}$ distribution with 10 degrees of freedom for buyers and 5 degrees of freedom for the seller. The average valuations will be closely approximated by the degrees of freedom. Consistency with the predictions of the theoretical model is not related to the scale of the reservation values. Lastly, we assume the cost of the transaction, $c_{i}$, is a constant equal to 1.0 , and this cost is actually incurred by the seller. These are the only inputs required to simulate the theory. 
Under pricing flexibility, a transaction occurs for those branches for which $b_{i}>s_{i}+c_{i}$. Total welfare is simply the sum of $b_{i}-s_{i}-c_{i}$ across all transactions. Since total welfare is the sum of the buyer and seller surplus, we ignore distributional issues for now. Under the benchmark case, 74 of 100 branches are exchanged and total welfare is 462 units.

The effect of regulation is measured by evaluating transactions and welfare at a regulated price, $r^{*}$. We assume the transaction occurs only when $r^{*}>b_{i}$ and $r^{*}>s_{i}+c_{i}$, so the seller can refuse transactions. To avoid assumptions about how the regulated price is set, we simply evaluate the number of transactions and welfare at all potential prices. ${ }^{82}$

\section{B. Results with Seller's Right to Refuse}

The results of the simulation are illustrated in Figure 3. In Panel A, we see that the aggregate economic welfare with regulation always lies below welfare under no regulation. As expected, "no regulation" dominates regulation at any price. In Panel B, we see that the number of transactions is lower under regulation than without regulation, which was also predicted by the theory. If transactions require investments, then investment likewise will decline. This demonstration of the theoretical results confirms that regulation (of any type) both reduces welfare and investments, if the seller can refuse a transaction.

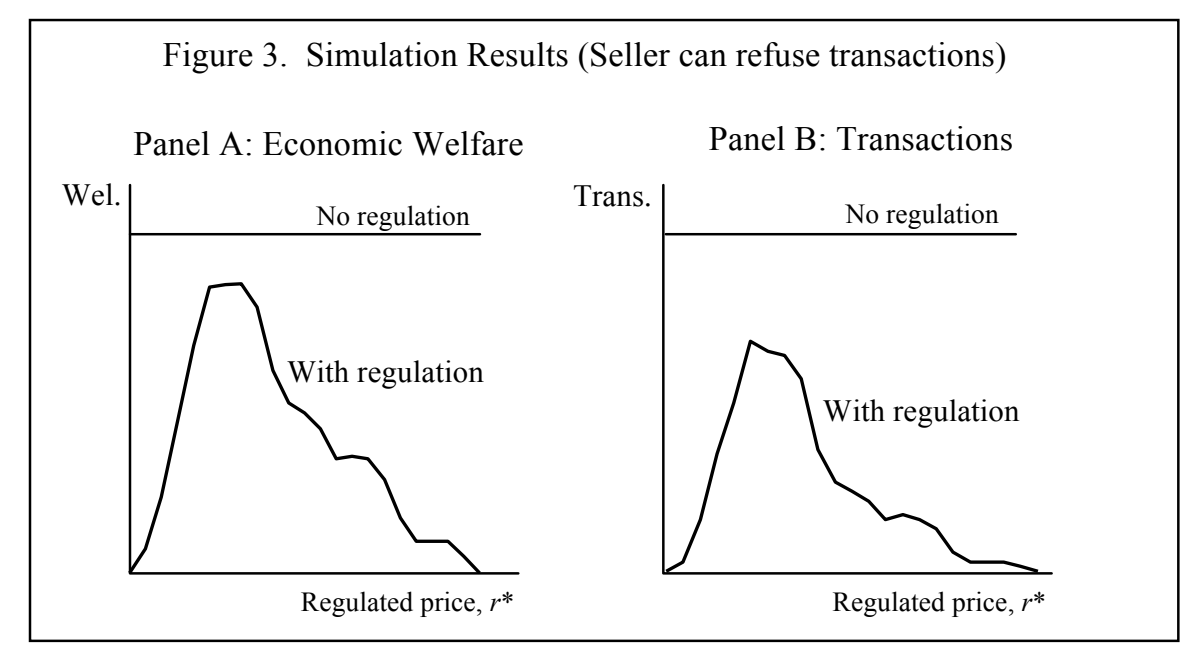

82 We consider integer prices only, but this has no effect on the results. 
Welfare in the unregulated state was 462 units and there are 74 transactions. At the peak of the regulated welfare, there are 368 units and 46 transactions. Note, however, that these figures are based on the assumed and arbitrary distributions of the simulation and are not representative of the expected welfare losses from regulation.

\section{Results with Seller Mandate to Provide}

In Figure 4 we illustrate the results under the assumption the seller cannot refuse a transaction when the buyer is willing. As before, welfare is always lower under regulation, which is illustrated in Figure 4, Panel A. Because regulation can force transactions that are welfare reducing $\left(r^{*}<s_{i}+c_{i}\right)$, Panel $\mathrm{B}$ shows that transactions may increase at very low prices. At plausible regulated prices (those not below cost on average), transactions are typically fewer than in the deregulated state, although this depends in part on the assumed distributions of values. However, seller profits are negative in most of these cases, so the firm would not operate at these low prices and no service would be sold at all. Interestingly, the seller earns negative profits at the welfare maximizing regulated price, so welfare maximization would not be an option for the regulator unless a transfer is arranged between buyers and sellers. But, again, these values are based on the arbitrary distributions of the valuations demonstrating only possibilities. The decline in welfare, whether or not the seller can refuse transactions, is true across all distributions of reservation values.

Figure 4. Simulation Results (Seller cannot refuse transactions)

Panel A: Economic Welfare Panel B: Transactions
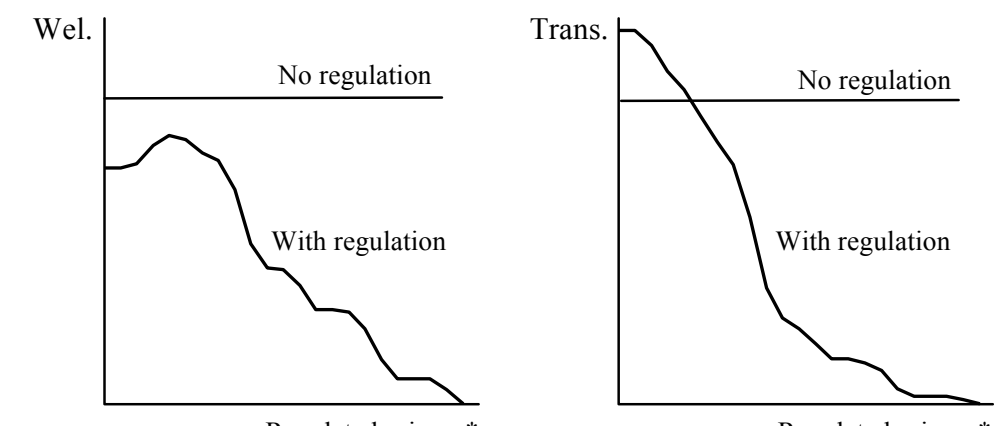

Regulated price, $r^{*}$

Regulated price, $r^{*}$ 
As a practical matter, the seller may find ways to avoid forced transactions, using regulatory proceedings, litigation, procedural delays, and so forth. Resources will be spent doing so, however, so this does not alter the fundamental result on welfare. Regulation reduces welfare. The negative and low profits at low regulated prices also may affect node investments, as discussed above.

From Figure 4, and to some extent from Figure 3, it is easy to see that the empirical observation that quantity rises when prices decline is not a reliable measure of the welfare effects of regulation (in contrast to the variable quantities framework). In a situation like Figure 4, Panel B, the number of transactions fall as the regulated price rises; lower prices render higher quantities consistent with the law of demand. But from Figure 4, Panel A, we see that welfare is always lower in the regulated state. In fact, even in the regulated state, it is possible for welfare to move in the opposite direction as quantity, as happens in Figure 4 at the lower end of the price range. Our conclusion that regulation reduces welfare and that there is no deadweight loss in the bilateral context we contemplate, cannot be discounted simply because price and aggregate quantity are inversely related in practice. Put simply, a regulatory slashing of prices need not improve welfare, even if quantity rises. This finding also casts doubt on the conclusions of studies making welfare arguments based on econometrically estimated demand curves for high-capacity services that conceptually rely on a variable quantities framework. ${ }^{83}$

\section{Distribution of Gains}

As we discussed in Section III.E above, the theory says nothing about how gains are distributed between buyer and seller, only that trade occurs when gains are positive. Much of the debate over special access pricing flexibility appears to be related to the distribution of gains, and not some overall welfare argument. We also noted that for every $\$ 1$ in regulation-induced increase in the profits of the buyer, there is always more than $\$ 1$ reduction in the wellbeing of the seller and the rest of society. Therefore, mandated redistributions of gains necessarily flunk the cost-benefit test.

We can demonstrate the cost-benefit calculation using the simulation. Keep in mind, however, that the values in the simulation are arbitrarily selected.

\footnotetext{
83 Shauntian Yao \& Lydia Gan, Monopoly Innovation and Welfare Effects, 4 ECON.: OPEN-ACCESS, OPEN-ASSESSMENT $\quad$ E-J. $1, \quad 8 \quad$ (2010), available at http://commcns.org/1pcfqPH.
} 
Size does not matter; the only question is whether the welfare costs exceed the benefits from a transfer.

The welfare costs of the transfer are computed by assuming all gains are captured by the seller in the deregulated state, and all gains are captured by the buyer in the regulated state. With this assumption, the change in welfare for every $\$ 1$ in transfer to the buyer is simply the ratio of the total welfare in the deregulated to the regulated state. Around plausible average price points, we compute that for every $\$ 1$ transfer of gains to the buyer, there is about a $\$ 1.4$ reduction in the well-being of all others. ${ }^{84}$ As expected from the theory, the costs exceed the benefits of regulation. This trade-off is a direct consequence of the assumed distribution, and should not be considered an estimate of the actual welfare trade-off.

\section{Conclusions}

The debate over whether high-capacity services should be subject to price regulation has raged for nearly fifteen years. ${ }^{85}$ To date, this debate has largely focused on whether there are sufficient competitive alternatives to warrant pricing flexibility and also on the geographic scope of any such deregulation. ${ }^{86}$ In this article, we show that under common characterizations of high capacity services, the core components of this debate are essentially irrelevant to the question as to whether price regulation would improve economic welfare. Indeed, if one assumes that high capacity services are provided by monopoly providers in highly granular, point-to-point markets (as proponents of special access regulation argue), then price regulation reduces welfare and probably reduces investment in communications infrastructure.

Our conclusions are based on an economic analysis of the exchange of a single good (i.e., a circuit or group of circuits) in the setting of bilateral monopoly, which is the scenario best matching the common characterizations of high capacity services markets by FCC decisions and those seeking regulation of these services. ${ }^{87}$ Our analysis suggests that nearly the entire body of empirical evidence and the standard conceptual arguments used to support increased

\footnotetext{
84 We compute the trade-off only at points with relatively high welfare and in the range of plausible average prices for transactions in the deregulated state.

85 The Need for Better Analysis of High Capacity Services, supra note 7, at 344.

86 Id. at 355-56.

87 See discussion supra Part II.A; see also In re Verizon Communications Inc. and MCI, Inc. Applications for Approval of Transfer of Control, Memorandum Opinion and Order, 20 F.C.C.R. 18,433, 18,449 \& n.90 (Nov. 17, 2005) (concluding that a "particular customer's location" is the market and citing the proponents of that conclusion).
} 
regulation for high capacity services are irrelevant. Under the conditions assumed, regulation reduces welfare, even if regulation is costless.

Most will find these results surprising, and many will find them frustrating or even unnerving. We stress that our findings derive from what we consider to be a fairly standard view over how high capacity services are ordered, provided, and consumed. The implications of our results are straightforward. First, under the conditions we describe, regulatory oversight over the provision of high capacity services by incumbents can essentially be eliminated, without fear of reductions in aggregate welfare. Second, there is hope that for this important class of service, the FCC can simultaneously satisfy the twin goals of the 1996 Telecommunications Act to "promote competition and reduce regulation" with regard to high capacity services. ${ }^{88} \mathrm{We}$ believe that policies that would promote entry of alternative high capacity service networks, including adjusting spectrum policy, access to poles, ducts, conduits, rights-of-way, and facilitating demand aggregation, will cut prices for end-users by reducing the number of locations of which there are monopoly sources of supply. Price regulation, alternately, may discourage competitive entry by reducing expected profits in the post-entry equilibrium. ${ }^{89}$ As always, the trade-offs must be contemplated and, ideally, quantified.

Our approach is focused upon maximizing welfare, which we believe is the proper method for making regulatory decisions in most settings. One risk of the regulatory state is that this balance may get lost if proponents of any one particular policy engage in rent-seeking lobbying or advocacy. A rigorous cost-benefit analysis focuses attention upon the overall good, and not simply upon the effects of a proposal upon the profits of one industry segment. A formal cost-benefit analysis of regulation helps ensure that policymakers not become enraptured by attention-grabbing talking points and instead insist that advocates provide a full and complete accounting of the real costs and benefits of any proposed regulatory action that are consistent with economic theory.

88 Telecommunications Act of 1996, Pub. L. No. 104-104, 110 Stat. 56, 56 (1996).

89 We use the word "may" with intention. High capacity services are sometimes purchased as an input. As such, lower prices may encourage entry under certain conditions. The question is empirical because there are conflicting effects (substitution and complementarity, jointly) of lower prices. See generally T. Randolph Beard et al., Mandated Access and the Make-or-Buy Decision: The Case of Local Telecommunications Competition, $45 \mathrm{Q}$. REV. ECON. \& FIN. 28 (2004). 